\section{MONGES SOB O MANTO DE GENERAIS: ARISTOCRACIA IMPERIAL GALO-ROMANA E MONASTICISMO NAS OBRAS DE SIDÔNIO APOLINÁRIO*}

\author{
Matheus Coutinho Figuinha**
}

RESUMO: As cartas e os poemas do nobre Sidônio Apolinário tendem a ser ignorados pelos estudiosos do monasticismo tardo-antigo. O presente texto é uma tentativa de preencher esta lacuna historiográfica. Meu objetivo é analisar as notícias de Sidônio acerca dos monges e monastérios de sua época, focando na relação da aristocracia imperial galo-romana com o monasticismo. As obras de Sidônio sugerem que, até o início da década de 480 , a aristocracia imperial galo-romana, de modo geral, pouco se envolveu com monges e assuntos monásticos. Mas, ao mesmo tempo, elas revelam o interesse que monges eruditos e taumaturgos podiam despertar em grandes aristocratas e o papel que estes podiam ter no governo e no cotidiano de determinados monastérios.

PALAVRAS-CHAVE: Sidônio Apolinário; Aristocracia Imperial GaloRomana; Monasticismo.

\section{MONKS UNDER THE GENERALS CLOAK: GALLO-ROMAN IMPERLAL ARISTOCRACY AND MONASTICISM IN THE WORKS OF SIDONIUS APOLLINARIS}

* Esta pesquisa

foi financiada pela

Fundação de Amparo

à Pesquisa do

Estado de São Paulo

(FAPESP).

** Universidade de

São Paulo (USP).

\begin{abstract}
The letters and poems of the noble Sidonius Apollinaris tend to be ignored by scholars of late antique monasticism. The present paper is an attempt to fill this historiographical gap. My purpose is to examine the information that Sidonius provides on monks and monasteries of his time, focusing on the relation of the imperial GalloRoman aristocracy to monasticism. The works of Sidonius suggest that, up to the beginning of the 480's, imperial Gallo-Roman aristocracy, in general, was little concerned with monks and monastic matters. But, at the same time, they reveal the interest that educated and thaumaturgical monks could stimulate in great aristocrats and the role that the latter could have in the government and daily activities of some monasteries.
\end{abstract}

KEYWORDS: Sidonius Apollinaris; Imperial Gallo-Roman Aristocracy; Monasticism. 
$1 \begin{aligned} & \text { s cartas e os poemas do nobre Gaio Sólio Apolinário Sidônio são fundamentais } \\ & \text { para o nosso conhecimento da aristocracia imperial galo-romana e da história } \\ & \text { política da Gália na segunda metade do século V. Samuel Dill (1899: 187) já }\end{aligned}$ reconhecia, no fim do século XIX, que "Não há relíquia daquela época mais preciosa para o historiador da sociedade do que as obras do bispo e grande senhor da Auvergne". ${ }^{1} \mathrm{E}$, de fato, desde a época do historiador inglês, as obras de Sidônio têm sido amplamente estudadas do ponto de vista histórico, literário e linguístico. ${ }^{2}$ Contudo, existem raros estudos dedicados ao que Sidônio revela sobre o monasticismo de sua época. ${ }^{3}$ A ideia corrente é a de que ele é, "de modo decepcionante, muito pouco informativo sobre o cenário religioso de Clermont" (Harries, 1994: 192). ${ }^{4}$ Com este artigo, espero preencher esta lacuna historiográfica. Meu objetivo é examinar as notícias de Sidônio sobre os monges e monastérios de seu tempo, focando na relação da aristocracia imperial galo-romana com o monasticismo.

\section{Monges SOB O MANTO DE GENERAIS}

Estamos acostumados a pensar as aristocracias ocidentais dos séculos IV e V amplamente fascinadas pela Igreja e pelo monasticismo (por exemplo, Nelson, 2001: 578; Brown, 2012: 415). Tantos aristocratas teriam sido ordenados clérigos ou teriam se tornado monges que um dos motivos da queda do Império romano, de acordo com alguns estudiosos, teria sido justamente a fuga de homens talentosos do governo e da administração para igrejas e monastérios (Frend, 1969: 1-11; Frend, 1974: 100-133; Momigliano, 1989: 23-27).

O único, porém, que delineou as etapas da progressiva aceitação do monasticismo pelas aristocracias ocidentais foi Jacques Fontaine. O estudioso argumenta que a primeira etapa estender-se-ia da propagação de notícias sobre o monasticismo egípcio no Ocidente, a partir da década de 330, à fundação de Marmoutier por Martinho de Tours, em 371. Já nesta primeira etapa, de acordo com Fontaine, "convém representar as elites dirigentes como largamente tocadas pela difusão da propaganda monástica" (Fontaine, 1979: 40). ${ }^{5}$ A segunda etapa situar-se-ia na década de 370, momento em que, "Através do escândalo, do sucesso de livraria, da propaganda epistolar, o monasticismo penetra por vontade ou por força nesta alta sociedade: ele atiça as imaginações, intriga e divide os espíritos, choca e conquista as

\footnotetext{
1 "There is no relic of that age so precious to the historian of society as the works of the bishop and grand seigneur of Auvergne" (Dill, 1899: 187).

${ }^{2}$ Seria impossível elencar aqui todos os estudos sobre Sidônio, mesmo nos restringindo aos mais importantes. Uma bibliografia completa pode ser encontrada no site www.sidoniusapollinaris.nl. Vale lembrar, em todo caso, que a melhor e mais recente biografia de Sidônio é a de Harries, 1994.

${ }^{3}$ As duas únicas exceções são Griffe, 1965: 142-148 e 324-325, e de Vogüé, 2003: 345-366.

4 "Sidonius himself is disappointingly uninformative about the religious landscape of Clermont in his day [...]" (Harries, 1994: 192).

5 “[...] il convient de se représenter les élites dirigeantes comme largement touchées par la diffusion de la propagande monastique" (Fontaine, 1979: 40).
} 
almas, de Trier a Aquilea, de Roma às ilhas dálmatas" (Fontaine, 1979: 43). ${ }^{6}$ A terceira etapa limitar-se-ia à década de 380, quando o monasticismo, de acordo com Fontaine, começou a regularizar-se e a suscitar "mais facilmente as vocações provindas da nobreza, de modo que as convergências de seus valores de vida com os da tradição antiga começam a chocar-se com os elementos brutalmente contestadores de suas formas de aparição primitivas" (Fontaine, 1979: 44). ${ }^{7}$ E a quarta etapa, finalmente, situar-se-ia nos anos de passagem do século IV ao século V. Fontaine sugere que, durante este período, o surgimento da literatura monástica latina teria começado a silenciar os últimos opositores do monasticismo. Teria também aparecido, em todas as regiões do Ocidente, a devoção monástica dos grandes latifundiários em suas willae, como Paulino de Nola, Sulpício Severo e Prudêncio de Calaguris.

Fontaine, portanto, traça uma difusão muito rápida do monasticismo entre as aristocracias ocidentais. Já no fim do século IV ou no início do século V seria possível encontrar, entre as aristocracias, um grande número de monges, que podiam viver em monastérios ou em suas próprias willae, e de devotos, que consumiam obras monásticas e admiravam monges carismáticos. Deste modo, os valores tradicionais destas aristocracias teriam sido abalados pelo monasticismo.

Em suas obras, Sidônio retrata as atividades políticas e cotidianas, os gostos e as ambições de uma aristocracia que, nas províncias sob a autoridade de Arles a partir de 418, manteve o monopólio da política imperial. ${ }^{8}$ Alguns de seus escritos são, também, as principais fontes literárias disponíveis para o estudo das villae tardo-antigas. ${ }^{9}$ Assim, poderíamos esperar encontrar em suas obras numerosos indícios da difusão do monasticismo na aristocracia imperial galo-romana, tais como menções a aristocratas que se converteram ou que eram devotos de homens santos. Contudo, a imagem que Sidônio oferece é que o monasticismo era quase totalmente ignorado por esta aristocracia. Comecemos com o que ele conta a respeito de monges aristocratas.

Entre 465 e 467, Sidônio dirigiu-se à milla de seu amigo Máximo, que havia sido oficial do Palácio (palatinus), para tratar do assunto de um cliente. Ao chegar, porém, Sidônio encontrou o amigo diferente de quanto o havia conhecido:

\footnotetext{
6 "Par le scandale, par le succès de librairie, par la propagande épistolaire, le monachisme pénètre alors de gré ou de force dans cette haute société: il y frappe les imaginations, intrigue les esprits et les divise, choque ou conquiert les âmes, de Trèves à Aquilée, de Rome aux îles dalmates” (Fontaine, 1979: 43). 7 “ "...] d'autant plus facilement les vocations issues de la noblesse que les convergences de ses valeurs de vie avec celles de la tradition antique commencent à l'y emporter sur les éléments brutalement contestataires de ses formes d'apparition primitives" (Fontaine, 1979: 44).

${ }^{8}$ Sobre as aristocracias e a situação política da Gália a partir de 418, os melhores estudos são os de Matthews, 1990: 329-351; Mathisen, 1993; Harries, 1994.

${ }^{9}$ Sidônio foi considerado um autor pouco confiável para o estudo das willae, pois suas descrições seriam demasiadamente dependentes de seus modelos literários. Cf. Percival, 1992: 158; Wood, 1992 : 9-18; Harries, 1994: 10 e 131; Percival, 1997: 279-292. Mais recentemente, contudo, ele tem sido reabilitado. Cf. Balmelle, 2001: 144-145; Dark, 2005: 331-342; Visser, 2014: 26-45.
} 
Seu hábito, seu caminhar, seu recato, sua aparência, sua linguagem eram os de um religioso; seus cabelos eram curtos, sua barba era longa, as cadeiras eram trípodes, os véus pendurados às portas eram de cilício; o leito não tinha nenhuma pluma, nem a mesa nenhuma púrpura; sua hospitalidade era tão benigna quanto frugal, menos abundante em carnes do que em legumes. Certamente, se um prato era mais saboroso, não era por indulgência para si, mas para os hóspedes (Epistola 4.24.3)..$^{10}$

Ao levantar-se da mesa, Sidônio perguntou discretamente aos outros convivas presentes "qual gênero de vida entre as três ordens ele havia abraçado, se era monge, clérigo ou penitente" (Epistola 4.24.4). ${ }^{11}$ Contaram-lhe, então, que Máximo havia sido ordenado padre pouco tempo antes, forçado pelos seus concidadãos. No dia seguinte, Sidônio conversou com Máximo enquanto seus clientes e escravos cuidavam dos animais.

Em uma carta do fim de 470 ou do início de 471, Sidônio elogia as "ações cotidianas" do inlustris Vécio, oferecendo-as aos seus leitores como exemplo a ser seguido. Após a morte da esposa, Vécio passou a viver como monge (monachus, religiosus) em sua uilla. Seu "novo gênero de vida" era tal que, nas palavras de Sidônio, ele era "monge não sob o pálio, mas sob o manto dos generais" (Epistola 4.9.3). ${ }^{12}$ A maior qualidade de Vécio era que sua casa emulava sua "perfeita pudicícia" (inlaesa pudicitia): os escravos eram solícitos, os banquetes aos hóspedes e aos clientes eram igualmente generosos e a bondade e a sobriedade reinavam em todos os espaços.

Outras qualidades de Vécio eram que, segundo Sidônio, ele:

não fica atrás de ninguém na criação, na apreciação e na condução de cavalos, cães e falcões; ele demonstra suma elegância nas roupas, refinamento nos cintos, esplendor nos ornamentos dos cavalos; seu andar é solene, seu espírito, sério (o primeiro lhe garante confiança pública, o segundo, dignidade privada); sua indulgência não favorece o vício, sua reprimenda não é cruel, e sua severidade tem justa medida, pois não é torpe, mas rígida (Epistola 4.9.2). ${ }^{13}$

\footnotetext{
10 "Habitus uiro, gradus, pudor, color, sermo religiosus, tum coma breuis, barba prolixa, tripodes sellae, Cilicum uela foribus appensa, lectus nil habens plumae, mensa nil purpurae, humanitas ipsa sic benigna quod frugi, nec ita carnibus abundans ut leguminibus; certe, si quid in cibis unctius, non sibi sed hospitibus indulgens" (Sidônio Apolinário, Epistola 4.24.3). Tradução do autor.

11 "[...] quod genus uitae de tribus arripuisset ordinibus, monachum ageret an clericum paenitentemue" (Sidônio Apolinário, Epistola 4.24.4). Tradução do autor.

12 "[...] nouoque genere uiuendi monachum complet non sub palliolo sed sub paludamento [...]" (Sidônio Apolinário, Epistola 4.9.3). Tradução do autor.

13 ' [...] in equis, canibus, accipitribus instituendis, spectandis, circumferendis nulli secundus; summus nitor in uestibus, cultus in cingulis, splendor in phaleris; pomposus incessus, animus serius (iste publicam fidem, ille priuatam asserit dignitatem); remissio non uitians, correptio non cruentans,
} 
Vécio, além disso, ouvia frequentemente a leitura das Escrituras enquanto comia, lia e cantava os salmos e abstinha-se de carnes, mesmo se dispondo a caçar. Sua moderação também aparecia no tratamento de seus escravos: "para com seus escravos domésticos, não é ameaçante ao proferir-lhes a palavra, nem desdenhoso ao aceitar um conselho, nem obstinado ao investigar um delito; rege o estado e a condição dos seus subordinados não segundo os direitos de propriedade, mas com discernimento" (Epistola 4.9.4). ${ }^{14}$ Vécio, enfim, cuidava da única filha, que era ainda pequena quando da morte da mãe, com "avita ternura, materna diligência e paterna benignidade" (Epistola 4.9.4). ${ }^{15}$

É muito provável que Filágrio, destinatário de uma carta de Sidônio de 469 ou 470, também fosse monge. Filágrio era provavelmente descendente do patrício homônimo (Sidônio Apolinário, Epistola 2.3.1; Poema 7.156-157) e, portanto, parente do imperador Ávito e de Magno Felix. Segundo Sidônio, Filágrio era admirado por "homens de nobre estirpe" (summates uiri) e era "instruído em todos os ramos da literatura" (Epistola 7.14.1). ${ }^{16}$ Filágrio gostava da companhia de "pessoas calmas" (quietr) e evitava a de "bárbaros" (barbari), dedicava-se diligentemente à leitura, encarnava a figura de um religioso (persona religiosi), não desejava os bens alheios e deleitava-se com a "companhia de pessoas instruídas" (contubernia eruditorum). Filágrio, além disso, era muito alegre, muito hospitaleiro, tratava seus escravos com "grande clemência" e jejuava em dias alternados. Por encarnar a figura de um religioso, é muito provável que Filágrio fosse monge. Sua hospitalidade e o tratamento que concedia aos seus escravos sugerem um regime semelhante ao de Vécio.

Alguns anos mais tarde, em 476/477, Sidônio enalteceu os ancestrais e a carreira de Tonâncio Ferreolo. Seus antepassados, relembra Sidônio na carta que lhe endereçou, haviam acumulado cadeiras curules e distinções patrícias, sendo seu avô materno, Flávio Afrânio Siágrio, o mais eminente: ele havia ocupado o proconsulado da África em 379, a prefeitura da Cidade em 381, a prefeitura do pretório em 382 e o consulado em uma data posterior (Sidônio Apolinário, Epístolas 1.7.4 e 7.12.1). ${ }^{17}$ Sidônio assegura que também o pai e os tios de Ferreolo haviam tido carreiras brilhantes (Epistola 7.12.1), mas desconhecemos os cargos que ocuparam. Ao casar-se com Papianila (Sidônio Apolinário, Poema 24.36-37), Ferreolo uniu-se à família de Ávito e, portanto, a Filágrio e ao próprio Sidônio.

Ferreolo era senador (Sidônio Apolinário, Epistola 1.7.9) e ocupou a prefeitura do pretório das Gálias entre 451 e 452/453. Como prefeito, cooperou com o magister militum

et seueritas eius temperamenti, quae non sit taetra sed tetrica" (Sidônio Apolinário, Epistola 4.9.2). Tradução do autor.

14 “"...] erga familiam suam nec in proferendo alloquio minax nec in admittendo consilio spernax nec in reatu inuestigando persequax; subiectorum statum condicionemque non dominio sed iudicio regit [...]” (Sidônio Apolinário, Epistola 4.9.4). Tradução do autor.

15 “[...] auita teneritudine, materna diligentia, paterna benignitate [...]" (Sidônio Apolinário, Epistola 4.9.4). Tradução do autor.

16 “[...] uirum omnium litterarum [...]” (Sidônio Apolinário, Epistola 7. 14.1). Tradução do autor. ${ }^{17}$ Sidônio Apolinário, Epistola 7.12.1, atribui triplices praefecturae a Siágrio, de modo que ele foi novamente prefeito da Cidade ou prefeito do pretório após 382. Cf. Jones, Martindale e Morris, 1971: 862. 
Aécio na campanha contra os hunos, em 451, persuadiu o rei Torismodo, graças unicamente à sua diplomacia, a abandonar o assédio a Arles, em 452/453, e reduziu os impostos que oneravam os proprietários gálicos, o que lhe garantiu grande reconhecimento (Sidônio Apolinário, Epistola 7.12.2).

Não é claro se Sidônio endereçou a carta a Ferreolo para congratulá-lo por ter sido ordenado padre ou se para consolá-lo, pois é possível que o presbiterado fosse considerado indigno de seu status social. ${ }^{18} \mathrm{Em}$ todo caso, é provável que sua ordenação tenha sucedido sua conversão ao monasticismo. Sidônio escreve: "[minha pluma] julgou ser mais justo se fosses posto entre os perfeitos de Cristo do que entre os prefeitos de Valentiniano" (Epistola 7.12.4). ${ }^{19}$ E, após designar Ferreolo como "o religioso mais humilde" (minimus religiosus), conclui a carta com a fórmula "ora por nós" (Orapro nobis), única em seu epistolário (Sidônio Apolinário, Epistola 7.12.4).

Como já observou Dill (1899: 207), Sidônio não concede muito espaço às mulheres em suas obras. Mas ele menciona duas monjas de origem aristocrática. A primeira, Frontina, era profundamente admirada pela família por causa de sua ascese rigorosa e de sua fé imensa. De acordo com Sidônio, ela teria sido "mais santa do que as santas virgens" (Epístola 4.21.4). Luce Pietri e Marc Heijmans (2013: 832) sugerem que ela provavelmente viveu, tendo feito o voto de virgindade perpétua, na casa dos pais. Ela era parente de Aper, membro de uma rica família senatorial. ${ }^{20}$ A segunda monja mencionada por Sidônio é Eutrópia, que, após a morte do marido, passou a fazer jejuns, doações aos pobres e longas vigílias. Sidônio refere-se a ela como "venerável matrona Eutrópia" e "santa Eutrópia" (Epístola 6.2.1 e 4). Podemos deduzir sua origem senatorial tanto da sua qualificação como matrona quanto da sua antiga amizade com Sidônio. ${ }^{21}$

\footnotetext{
${ }^{18}$ Sidônio Apolinário, Epístola 7.12.4: "Neque te sacerdotibus potius admixtum uitio uertat malignus interpres; nam grandis ordinum ignorantia tenet hinc aliquid derogaturos, quia, sicuti cum epulum festiuitas publica facit, prior est in prima mensa conuiua postremus ei, qui primus fuerit in secunda, sic absque conflictatione praestantior secundum bonorum sententiam computatur honorato maximo minimus religiosus". Martindale, 1980: 466, supõe que a carta de Sidônio não indique que Ferreolo havia sido ordenado padre, mas apenas que "[...] he was now living a devout Christian life worthy of a priest [...]". Contudo, se Ferreolo não havia sido ordenado padre, sua associação a sacerdotes não tem sentido.

19 "[...] censuitque iustius fieri si inter perfectos Christi quam si inter praefectos Valentiniani constituerere" (Sidônio Apolinário, Epistola 7.12.4). Tradução do autor.

${ }^{20}$ Sobre Aper, cf. Stroheker, 1948: 145; Martindale, 1980: 109; Heinzelmann, 1982: 555; Pietri e Heijmans, 2013: 158-159. Pietri e Heijmans (2013: 832) supõem que Aper fosse "cousin germain" de Frontina, mas não há indícios que nos permitam saber o exato grau de parentesco entre ambos. Stroheker (1948: 145 e 176), Martindale (1980: 109 e 486) e Heinzelmann (1982: 555 e 611) confundem Frontina com a tia materna de Aper, mas eram duas pessoas diferentes. Cf. Sidônio Apolinário, Epistola 4.21.4: "Sed et matertera tua hinc, et hinc fuit $[\ldots]$ Frontina $[\ldots]$ ".

${ }^{21}$ Seria ela parente do nobre senador Eutrópio, grande amigo de Sidônio? Sobre Eutrópio, cf. Stroheker, 1948: 171; Martindale, 1980: 444-445; Heinzelmann, 1982: 604; Pietri e Heijmans, 2013: 723-724.
} 
De todos os membros da aristocracia imperial galo-romana que figuram nas obras de Sidônio, apenas seis eram monges - ou sete, se aceitarmos que Claudiano, sobre o qual falaremos a seguir, também pertencia a esta aristocracia. Qualquer um destes números é incrivelmente baixo se considerarmos a tese de que o monasticismo havia amplamente se difundido entre as aristocracias ocidentais até o início do século V. É claro que ambos os números (seis ou sete) não são conclusivos. Sidônio não mencionou todos os seus colegas, nem mesmo todos os seus colegas que se converteram. ${ }^{22}$ Para termos uma ideia mais precisa do significado destes números para a propagação do monasticismo na aristocracia imperial galo-romana, em particular, precisamos de estudos sobre outros autores e outras regiões do Ocidente para obtermos dados de comparação. Temos, de qualquer modo, números que não podem ser ignorados nos estudos sobre a difusão do monasticismo entre as aristocracias.

Acerca da devoção de grandes aristocratas por monges e monastérios, Sidônio é igualmente silencioso. Em uma carta a Volusiano, sobre a qual falaremos em breve, ele conta que Vitório, conde da Auvergne, ${ }^{23}$ havia chorado a morte de um monge taumaturgo sírio, Abraão, e lhe pagado um funeral digno de um padre (Epistola 7.17.1). É muito provável também que Volusiano fosse um grande patrono do monastério que Abraão havia fundado em Clermont. E, em outra carta, Sidônio menciona que Domnulo, poeta e quaestor sacri palatii durante o reino de Majoriano, ${ }^{24}$ hospedava-se frequentemente nos monastérios do Jura (Epistola 4.25.5).

$\mathrm{O}$ que os indícios sobre monges e monastérios nos escritos de Sidônio sugerem é que, até o início da década de 480 (data de suas cartas mais tardias), o monasticismo propagou-se muito pouco na aristocracia imperial galo-romana. Poder-se-ia argumentar que Sidônio, em suas obras ou na seleção que operou das mesmas, decidiu não tratar de monges e monastérios, de modo que os indícios que ele revela não são, de modo algum, indicativos da difusão do monasticismo. Não penso, contudo, que Sidônio tenha tomado tal decisão. Ele descreveu os regimes de Máximo, Vécio, Filágrio e Ferreolo justamente para elogiá-los e apresentá-los como modelos a serem seguidos. Além disso, ele escreveu a outros três amigos tentando convencê-los a adotar um regime semelhante ao de Vécio (Epistolas 4.13, 4.15, 8.4). ${ }^{25}$ Se muitos outros de seus colegas tivessem se convertido, Sidônio teria certamente dado mais notícias acerca da difusão do monasticismo na aristocracia imperial galo-romana.

\footnotetext{
${ }^{22}$ Sidônio não trata da conversão de Magno Felix e Rurício de Limoges. As obras de Sidônio que os mencionam ou que lhes são endereçadas são anteriores à sua conversão. Sobre ambos os personagens, cf. Pietri e Heijmans, 2013: 749-751 (Felix) e 1635-1649 (Rurício).

${ }^{23}$ Sobre Vitório, cf. Martindale, 1980: 1162-1164; Heinzelmann, 1982: 714; Pietri e Heijmans, 2013 : 1955.

${ }^{24}$ Sobre Domnulo, cf. Stroheker, 1948: 164; Martindale, 1980: 374; Heinzelmann, 1982: 593; Pietri e Heijmans, 2013: 591-592.

${ }^{25}$ Pietri e Heijmans (2013: 511) sugerem que Consêncio, destinatário da Epístola 8.4, "rendeu-se sem dúvida às exortações de Sidônio, pois, em uma carta pouco anterior à publicação do livro IX de sua correspondência [Epístola 9.15.1, vv. 23-28], em 483, Sidônio evoca no passado a atividade literária de seu amigo”. O argumento de Pietri e Heijmans, contudo, é muito frágil. Tanto que, nos vv. 19-22 da
} 
Os regimes adotados pelos amigos de Sidônio podiam ser bem diferentes um do outro. ${ }^{26}$ Máximo abandonou a aparência, a postura e as roupas que o identificavam como aristocrata. Ele também se desfez dos objetos luxuosos de sua villa, embora continuasse a oferecer banquetes aos hóspedes e a manter clientes e escravos. Vécio, por outro lado, continuou a apresentar-se e a viver como um grande aristocrata: ele manteve a elegância das vestes, a altividade da postura, a riqueza dos ornamentos dos cavalos, a apreciação e a criação de animais, a dedicação à caça e os fartos banquetes a clientes e hóspedes. Seu regime resumia-se na castidade, na leitura da Bíblia, no canto dos salmos, na abstinência de carnes, na solicitude para com a filha e no comedimento para com os escravos.

Mas, apesar das diferenças, os regimes dos quatro amigos de Sidônio apresentavam semelhanças notáveis entre si. Em primeiro lugar, eles converteram-se após toda uma carreira a serviço do Império: Máximo havia sido oficial do Palácio; Vécio era inlustris, o que indica que ele havia ocupado cargos públicos; Filágrio era parente do imperador Ávito, o que havia lhe aberto as portas da política imperial; ${ }^{27}$ e Ferreolo havia sido prefeito do pretório das Gálias. Em segundo lugar, os quatro moravam em suas villae. Nenhum deles decidiu transferir-se para um monastério. E, em terceiro lugar, eles não adotaram uma disciplina de restrições materiais. Mesmo Máximo, que retirou os objetos luxuosos de sua nilla, continuou receber seus hóspedes com banquetes e a cercar-se de clientes e escravos. Nenhum deles sentiu a necessidade de dedicar suas riquezas a um santo ou a Deus, como Paulino de Nola havia feito duas gerações mais cedo. ${ }^{28} \mathrm{E}$ é justamente por sua moderação que são tão elogiados por Sidônio.

Máximo, Vécio, Filágrio e Ferreolo, assim como diversos outros personagens, foram qualificados por Élie Griffe (1965: 83-84, 128-151 e 299-302) como conuersi. Os conuersi, segundo o autor, eram "pios saeculares", ou seja, "cristãos ferventes que, mesmo permanecendo no século, preocupavam-se em realizar o ideal cristão" (Griffe, 1965: 128). ${ }^{29}$ Estes "cristãos ferventes", vistos por Griffe como numerosos, retiravam-se, quando se sentiam fortemente atraídos pela vida monástica, à proximidade dos monges ou, como era o caso da maioria, em

mesma carta, Sidônio afirma que Leão ou Consêncio aptius parauerit o poema desejado por Gelásio. O futuro perfeito indica que Consêncio ainda compunha e que ele, assim, iria compor uma poesia para Gelásio.

${ }^{26}$ Trato apenas de Máximo, Vécio, Filágrio e Ferreolo porque as menções a Frontina e Eutrópia não só são muito breves, como também não revelam nada que acrescente aos estudos mais recentes. Sobre o monasticismo feminino na Antiguidade Tardia, há uma bibliografia enorme. Entre os estudos mais influentes, cf. Clark, 1979; Clark, 1986; Brown, 1988: 241-284; Elm, 1994. Em português, cf. Silva, 2006a: 321-352; Silva, 2006b: 40-59; Silva, 2007: 63-78; Figuinha, 2009: 93-97; Figuinha, 2010: 155-173; Silva, 2012: 31-49.

${ }^{27}$ Como foi o caso de Sidônio, que ocupou um cargo palatino também durante o reinado de Ávito (455-456), seu sogro.

${ }^{28}$ Sobre Paulino, cf. Trout, 1999.

29 “[...] des chrétiens fervents qui, tout en restant dans le siècle, se préoccupent de réaliser l'idéal chrétien" (Griffe, 1965: 128). 
suas casas ou uillae. Em todos os casos, contudo, seu regime era marcado pelo comedimento na comida e nas roupas, pela leitura frequente dos livros bíblicos, pela presença nos ofícios litúrgicos e pela continência sexual (Griffe, 1965: 129).

Griffe reconhece que, no início do chamado movimento monástico, não era sempre possível distinguir um monge de um conuersus. Mas, para ele, o monge distinguia-se do conuersus por fazer parte de "uma espécie de monastério" e, consequentemente, por viver "em uma separação maior com o mundo" (Griffe, 1965: 300) $\cdot{ }^{30}$ Esta suposta separação manifestavase de três modos: o monge não podia viver ao lado de mulheres e, sendo casado, de sua esposa, enquanto o conuersus podia; o monge vestia apenas um simples manto (pallium) sobre a túnica, enquanto o conuersus podia vestir outras roupas, mesmo que austeras e pobres; e os monges buscavam a solidão. Era a busca da solidão que, para Griffe, dava "à vida monástica seu caráter mais distintivo" (Griffe, 1965: 301-302). ${ }^{31}$

Com esta classificação, Griffe tenta organizar de modo taxonômico uma realidade confusa e até mesmo contraditória em alguns momentos. Como resultado, ele pinta um retrato bastante arbitrário do monasticismo na Gália dos séculos IV e V. Tanto é que ele caracteriza como conuersi Paulino de Nola, Sulpício Severo e outros, que eram considerados monges por seus contemporâneos, ${ }^{32}$ simplesmente porque eles não viviam em monastérios. Hoje já se reconhece que os monastérios, na prática, não estavam isolados do mundo, como supunha Griffe. ${ }^{33}$ Além disso, nem todos os personagens que ele identifica como conuersi seguiam todas as normas do regime que, para ele, qualificava-os como tais (como, por exemplo, Vécio, que continuou a vestir-se com toda a pompa de um rico aristocrata). Assim, para lidar com o monasticismo nos escritos de Sidônio, precisamos reconhecer a enorme variedade de formas monásticas à época. Se Máximo, Vécio, Filágrio e Ferreolo eram considerados monges por seus contemporâneos, nós também devemos considerá-los tais.

Os escritos de Sidônio apresentam uma aristocracia cristã, ${ }^{34}$ mas que, com a exceção de poucos casos, não foi afetada pelo monasticismo. Tratava-se de uma aristocracia que continuava a almejar cargos públicos e riquezas tanto quanto havia feito no século IV. ${ }^{35}$ É

\footnotetext{
30 "La perfection du moine consiste dans une séparation plus grande d'avec le monde" (Griffe, 1965: $300)$.

31 “[...] c'est la recherche de la solitude qui donne à la vie monastique son caractère le plus distinctif" (Griffe, 1965: 301-302).

${ }^{32}$ Em uma carta a Sulpício Severo, Paulino considera-se monachus e afirma morar em um monasterium (Paulino, Epistola 5.14 e 15). Para o uso de Paulino de ambos os termos, cf. Lienhard, 1977: 63-65 e 67-69. Agostinho, na sua Epistola 26.5, chama Paulino de Dei seruus, o mesmo epíteto que dava aos monges ao seu redor, e Jerônimo, na sua Epistola 58.5, considera Paulino monachus.

${ }^{33}$ Graças, sobretudo, ao livro de Brown, 1988.

${ }^{34}$ Cf. as Epistolas 3.1, 4.15, 8.4.1, e o Poema 22.218.

${ }^{35}$ Cf., por exemplo, Sidônio Apolinário, Epistola 8.8 .
} 
por isto que Máximo, Vécio, Filágrio e Ferreolo converteram-se após uma carreira a serviço do Império. Uma possível exceção foi Claudiano Mamerto.

\section{Claudiano Mamerto, Fausto e Lupo}

Claudiano Mamerto ${ }^{36}$ compôs um tratado sobre $A$ natureza da alma e um hino em versos (Sidônio Apolinário, Epístola 4.3.8), que se perdeu. Não fossem os escritos de Sidônio, todavia, não teríamos quase nenhuma informação a seu respeito.

Sidônio conta que Claudiano converteu-se ao monasticismo ainda jovem (Epístola 4.11.6) e que, em seguida, abandonou todas as suas propriedades (Epistola 4.11.4). Ele era certamente de origem aristocrática, embora seja impossível determinar se curial ou senatorial. ${ }^{37}$

Claudiano foi ordenado padre em Vienne em uma data não determinada. Nesta posição, atuou como ajudante de seu irmão mais velho, Mamerto (Sidônio Apolinário, Epistola 4.11.5 e 6; Genádio, Os homens ilustres 84), consagrado bispo da mesma cidade entre 449 e 463: era conselheiro na episcopalis audientia, administrador das igrejas, de suas propriedades e de seus rendimentos, companheiro nas leituras e nas viagens e intérprete na exegese (Sidônio Apolinário, Epistola 4.11.5). Por causa de sua habilidade em musicar salmos, era responsável por formar e ensinar os coros que cantavam nas igrejas. E, para as festas solenes, separava as leituras bíblicas adequadas e determinava o momento em que deviam ser lidas (Sidônio Apolinário, Epistola 4.11.6). Claudiano, porém, assistia não só ao irmão, mas também aos outros clérigos, além de pregar a membros da comunidade, pagar a soltura de prisioneiros e distribuir esmolas (Sidônio Apolinário, Epístola 4.11.4).

Claudiano nutriu por Sidônio uma grande amizade. Entre 469 e 470, ao dedicar-lhe A natureza da alma, saúda-o como "irmão amadíssimo” (A natureza da alma, prefácio, 1.1) e, entre o fim de 470 e o início de 471, escreve-lhe uma carta apresentando-se como seu "amigo particular e íntimo" (Sidônio Apolinário, Epistola 4.2.4). Sidônio, de fato, compôs o grupo que frequentou a casa de Claudiano na década de 460 e, a partir de então, manteve enorme interesse pela atividade intelectual do amigo. Tanto é que Claudiano afirma ter sido incitado por "grandes homens", especialmente Sidônio, a escrever seu tratado (A natureza da

\footnotetext{
${ }^{36}$ Como notam Pietri e Heijmans (2013: 481), o nome Mamertus Claudianus aparece uma única vez nas fontes (Sidônio Apolinário, Epístola 5.2.1). Em todos os outros casos, ele é denominado apenas Claudianus.

${ }^{37}$ A origem aristocrática de Claudiano pode ser deduzida não só do fato de que ele abandonou todos os seus bens após sua conversão, mas também da sua sólida formação. É possível que, enquanto estava em Lyon e participava das discussões promovidas por Euquério, na década de 440, frequentasse a escola de gramática e retórica. Além disso, ele teve os meios para, após sua conversão, dedicar-se aos estudos e adquirir livros em grego e latim. Trataremos logo abaixo da formação de Claudiano. Se seu irmão Mamerto for identificado com o nobre e rico Mamerto da Vida de Aniano (Vita Aniani 5: “[...] Mamertus adprime nobilis, multum in omnibus rebus locupletus [...]"), Claudiano era muito provavelmente de família senatorial.
} 
alma, prefácio) e, na carta apenas mencionada (Sidônio Apolinário, Epistola 4.2), questiona porque o amigo ainda não havia respondido à dedicatória.

Sidônio não respondeu a Claudiano muito provavelmente porque seu tratado contestava as teses de Fausto, outro amigo íntimo de Sidônio, sobre a corporeidade da alma (Alciati, 2009: 201-203). Sidônio, contudo, nunca escondeu sua profunda admiração pelos conhecimentos e pela erudição de Claudiano. Em 471, referiu-se a ele como "o filósofo mais competente dos cristãos e o primeiro de todos os sábios" (Epistola 5.2.1) e, poucos anos depois, com o mesmo entusiasmo, qualificou-o como "o homem mais inteligente de sua época, de sua região, de seu povo" (Epistola 4.11.1). Na década de 440, Claudiano frequentou as eruditas disputationes promovidas pelo bispo Euquério, em Lyon (Claudiano, $A$ natureza da alma 2.9). E, após sua conversão monástica, assimilou “em isolamento" (secreta... institutione) os conhecimentos romanos, gregos e cristãos (Sidônio Apolinário, Epístola 4.11.6). De acordo com Sidônio, Claudiano dominava não só a oratória, a dialética, a poesia, a exegese, a geometria e a música (Epistola 4.11.6), mas também a filosofia, a astronomia, a aritmética e a arquitetura (Epístola 4.3.5). Foi no período de otium de 461 a 467 que Sidônio participou do grupo de intelectuais que se reunia na casa de Claudiano (Harries, 1994: 107). Nas reuniões, Claudiano discursava e um dos ouvintes era escolhido para apresentar os "silogismos" opostos. Claudiano refutava um a um e respondia a todas as questões, inclusive, para o benefício da discussão, àquelas formuladas pelos "ignorantes e imperitos" (idiotarum... imperitorumque) (Sidônio Apolinário, Epistola 4.11.2-3). ${ }^{38}$

Claudiano morreu entre 471, data da última carta conhecida de Sidônio endereçada a ele (Epistola 4.3), e 477, data da publicação da carta em que Sidônio transmite o epitáfio que escreveu para o amigo (Epistola 4.11). André Loyen (2003b: 252) sugere que Claudiano morreu, mais precisamente, em 471/472 ou em 474/475, tendendo para a primeira possibilidade por causa da proximidade entre as cartas 4.11 e 9.9.16 de Sidônio. Sabemos que Sidônio não pôde participar do funeral do amigo por causa do assédio dos visigodos a Clermont. Ele visitou sua tumba e compôs seu epitáfio pouco depois, durante o inverno (momento em que o cerco à cidade era interrompido). Na carta 5.6.1, de outubro de 474, Sidônio conta ao tio ter passado por Vienne. Esta pode ter sido a ocasião em que Sidônio homenageou o amigo falecido. Neste caso, poderíamos datar a morte de Claudiano entre a primavera e o início do outono de $474,{ }^{39}$ mas não existem indícios de que Sidônio tenha prestado as homenagens especificamente durante esta viajem.

A relação de Claudiano com o monasticismo foi diferente da de um Máximo ou um Vécio. Ele não se converteu após uma carreira na administração ou no governo do Império, mas ainda jovem. E, uma vez convertido, dedicou-se quase exclusivamente aos livros. Estas diferenças, contudo, não indicam que sua conversão manifestou-se de modo radical, com a dispersão de seu patrimônio. Como apontam alguns estudiosos, um aristocrata que, por

\footnotetext{
${ }^{38}$ Para os conhecimentos de Claudiano a partir da estrutura do De statu animae, cf. Alciati, 2009: 204-209.

${ }^{39}$ Pietri e Heijmans (2013: 484), partindo deste mesmo raciocínio, datam a morte de Claudiano entre o fim de 473 e o início de 474. Porém, se Claudiano tivesse de fato morrido naquele período, que era inverno, Sidônio poderia ter ido ao funeral do amigo.
} 
motivos religiosos, quisesse alienar suas propriedades devia antes satisfazer as reivindicações da cúria, talvez com a doação de uma parte à cidade, e dos familiares, dando-lhes a possibilidade de comprar o que seria doado ou vendido. Além disso, ele podia encontrar oposição das autoridades civis e eclesiásticas (Giardina, 1988: 130; Trout, 1999: 145-146; Brown, 2012: 168-169 e 217-218). Claudiano, portanto, deve ter simplesmente abdicado a herança a favor do irmão ou dos irmãos e continuando a depender do patrimônio familiar para a própria subsistência e a aquisição de livros.

Sidônio manteve contato, além de Claudiano, com dois monges-bispos oriundos de Lérins, Fausto e Lupo. Do primeiro, Sidônio elogia o rigor da disciplina ascética (Epístola 9.3.4), mas é o estilo (genus dictandi), a eloquência (facundia, uirtus perorandi) e a inteligência (ingenium) que ele mais admira (Epistolas 9.3.1 e 5; 9.9.9-15). Fausto teria dominado os conhecimentos (disciplinae) espirituais e forenses, mantendo, porém, o justo equilíbrio entre as regras de ambos (Epístola 9.3.5). A respeito de um tratado de Fausto (comumente identificado com o De gratia), Sidônio sugere que própria filosofia havia se convertido:

a filosofia, tendo sido violentamente tomada do número das artes sacrílegas, tendo raspado o cabelo da religião supérflua e retirado a sobrancelha da ciência secular, e tendo alisado as rugas da veste antiquíssima, isto é, as dobras da nociva dialética que ocultam os erros dos costumes e as ilicitudes, uniu-se a ti, com os membros purificados, em um místico abraço (Epistola 9.9.12)..$^{40}$

De Lupo, foram também a eloquência (facundia, eloqui tui claritas) e a gravidade (grauitas), mais do que as "fatigantes vigílias" em Lérins (Epistola 6.1.3), que chamaram a atenção de Sidônio (Epistolas 6.1.3; 9.11.1 e 9). Lupo era inclusive um leitor das obras de Sidônio (Sidônio Apolinário, Epistola 9.11).

Philip Rousseau (1976: 369-370) sugere que Claudiano, Fausto e Lupo contribuíram para que Sidônio aceitasse o surgimento, na Gália, de uma elite baseada apenas no conhecimento. "A proeminência cada vez maior de líderes monásticos e o triunfo do barbarismo", de acordo com Rousseau, estariam por trás da afirmação de Sidônio de que "o único indício de nobreza será o conhecimento das letras", não mais o "grau das dignidades [públicas]" (Epistola 8.2.2). ${ }^{41}$ Em minha opinião, por trás destas palavras estava, simplesmente, o fim do governo imperial no Ocidente. ${ }^{42}$ Não vejo como uma suposta proeminência de líderes

40 “[...] philosophiam scilicet, quae uiolenter e numero sacrilegarum artium exempta raso capillo superfluae religionis ac supercilio scientiae saecularis amputatisque peruetustarum uestium rugis, id est tristis dialecticae flexibus falsa morum et illicita uelantibus, mystico amplexu iam defaecata tecum membra coniunxit” (Sidônio Apolinário, Epistola 9.9.12). Tradução do autor.

41 “[...] nam iam remotis gradibus dignitatum [...], solum erit posthac nobilitatis indicium litteras nosse" (Sidônio Apolinário, Epistola 9.2.2). Tradução do autor.

${ }^{42}$ Isto não significa que um aristocrata, após a queda do Império romano, em 476 (esta carta é datada de 478), não pudesse mais ocupar cargos públicos. Certamente podia, mas nas cortes dos reis germânicos. Cf. Mathisen, 1993. Nesta carta (8.2.2), contudo, Sidônio apresenta-se orgulhosamente 
monásticos possa ter contribuído para a decepção de Sidônio. Suponho, diferentemente de Rousseau, que Claudiano, Fausto e Lupo permitiram que Sidônio aceitasse o monasticismo. Sidônio sempre nutriu uma intensa paixão pelas letras. Mesmo tendo pensado, após sua ordenação à cátedra de Clermont, que a composição de poemas era incompatível com o episcopado (Epistola 9.12), ele não abdicou de sua cultura clássica. Ele jamais teria admirado os monges que negavam a validade desta cultura ou que a consideravam incompatível com o cristianismo. Mas Claudiano, Fausto e Lupo também eram apaixonados pelas letras. Sidônio, com eles, podia conversar sobre questões filosóficas e literárias e, neles, podia admirar o justo balanço entre as virtudes cristãs e os conhecimentos pagãos.

\section{Monges SOb O PÁlio E A DEVOÇão dA ARISTOCRACIA IMPERIAL}

Em suas obras, Sidônio fala pouco da devoção de aristocratas a monges e monastérios, mas uma de suas cartas, em particular, suscita questões importantes a respeito. Em março de 476, Sidônio respondeu ao pedido de Volusiano de compor um canto fúnebre em versos elegíacos ao monge recém falecido Abraão. Na peça que compôs (Epístola 7.17.2), Sidônio conta que Abraão nasceu na Mesopotâmia e que lá foi preso por causa da perseguição aos cristãos promovida pelo rei Izdegerdes II a partir de 451. Abraão, contudo, conseguiu fugir da prisão cinco anos mais tarde e, então, embarcou em uma série de viagens em que passou por Roma, Constantinopla, Jerusalém, Alexandria, Antioquia, Cartago, Ravenna e Milão. Abraão logo adquiriu a reputação de taumaturgo e, por onde passou, afugentou os demônios. Ele instalou-se finalmente em Clermont, em um "pobre retiro" (paupertinus recessus), onde construiu uma cabana (casa) com teto de palha e uma igreja.

$O$ retiro de Abraão em Clermont logo se transformou em monastério, que foi então dedicado a são Círico. De acordo com Gregório de Tours, Abraão podia expulsar os demônios, dar a visão aos cegos e curar outras doenças. Mas uma vez, por ocasião da festa de são Círico, realizou um grande milagre. Abraão ordenou ao superior do monastério que servisse vinho aos fiéis reunidos na igreja. O superior, porém, informou-lhe que não havia vinho suficiente para “o bispo, o conde e os cidadãos”. Então Abraão começou a orar na dispensa e seu pedido foi atendido: todos beberam abundantemente, mas a jarra não se esvaziou (Gregório, Vida dos Padres 3).

Gregório narra o milagre de Abraão, mas é Sidônio quem nos informa sobre a devoção de Vitório, conde da Auvergne, ao monge. Como já mencionei, Sidônio conta que Vitório chorou a morte de Abraão e pagou-lhe o velório de um padre (Epístola 7.17.1). Não sabemos se a devoção do conde ao monge começou ou intensificou-se por causa do milagre. Mas podemos estar certos de que ela manifestava-se no auxílio financeiro ao próprio Abraão ou ao seu monastério.

como membro da aristocracia que havia mantido o monopólio da política imperial na Gália. Assim, ele afirma serem dignos dos membros de sua ordo apenas os cargos a serviço do Império, desdenhando a carreira nas cortes germânicas. 
Apesar da devoção particular de Vitório a Abraão, foi a Volusiano que Sidônio, após a morte do monge, pediu: "tenta consolar seus discípulos nos princípios nos quais te exceles e reforma rapidamente a regra flutuante dos irmãos desamparados segundo os estatutos dos Padres de Lérins ou de Grigny" (Epistola 7.17.3). ${ }^{43}$ Sidônio deu ao senador a autoridade de castigar os que se opusessem e de congratular os que se submetessem.

A autoridade de Volusiano no monastério era maior que a do próprio abade, um homem santo, mas, "um pouco mais do que o apropriado, de corpo fraco e de espírito tímido, mais disposto a obedecer do que a ordenar" (Epistola 7.17.4). ${ }^{44}$ O próprio abade teria pedido assumir a direção do monastério sob a autoridade de Volusiano, para que o mesmo o ajudasse a disciplinar os "mais jovens". Sidônio pede, então, que Volusiano fosse "superior ao próprio abade” (Epistola 7.17.4).

A questão curiosa é que Volusiano, ao contrário do que supõem os estudiosos (Griffe, 1965: 325; Loyen, 2003c: 195; de Vogüé, 2003: 356; Alciati, 2009: 141; Pietri e Heijmans, 2013: 2003), não era monge. ${ }^{45}$ Ele era um rico senador (Rurício, Epistola 2.65; Gregório, Dez livros de histórias 2.26 e 10.31), visto por Sidônio como um irmão, um amigo e um companheiro de armas (Epistola 7.17.3), e era casado. Anos mais tarde, Rurício de Limoges caçoará de sua submissão à esposa (Epístola 2.65). Não conheço nenhum outro caso em que uma autoridade maior que a do próprio abade tenha sido concedida a um laico (fosse ele monge ou não). Como explicar tal concessão? Pode ser que Volusiano fosse padre em Clermont, apesar de sua posição não ter sido mencionada. Ou, então, que Sidônio tenha levado em conta a amizade que nutria por ele. Em minha opinião, contudo, só podemos entender a autoridade que Volusiano recebeu se assumirmos que ele era o maior patrono do monastério.

Aristocratas aparecem como patronos de monges e monastérios da Gália desde as três últimas décadas do século IV, mas os indícios são muito escassos. Sulpício Severo (Diálogos 3.14.5) afirma que Licôncio, um ex-vicário, doou cem libras de prata a Martinho de Tours. Hilário (Vida de Honorato 21.1) conta que um rico devoto, no início do século V, encheu o cofre (arca) de Honorato, abade de Lérins, dedicado ao cuidado dos pobres. E o anônimo autor da Vida dos Padres do Jura (145) refere-se a Siágria, pertencente a uma das famílias mais importantes da Gália, ${ }^{46}$ como "mãe de igrejas e monastérios".

Por um lado, a escassez de notícias sobre ricos patronos de monges e monastérios na Gália dos séculos IV e V parece confirmar a impressão que Sidônio nos dá de que

\footnotetext{
43 “ [...] tu quoque quibus emines institutis discipulos eius aggredere solari fluctuantemque regulam fratrum destitutorum secundum statuta Lirinensium patrum uel Grinnicensium festinus informa [...]” (Sidônio Apolinário, Epístola 7.17.3). Tradução do autor.

44 “[...] uir $[\ldots]$ plusculum iusto et corpore infirmus et uerecundus ingenio eoque parendi quam imperandi promptior [...]” (Sidônio Apolinário, Epístola 7.17.4). Tradução do autor.

${ }^{45} \mathrm{O}$ epíteto domine frater, que Sidônio atribui a Volusiano (Epistola 7.17.1), explica-se pela amizade que ambos nutriam um com o outro, não pelo suposto pertencimento de Volusiano ao monastério de Abraão. Se Sidônio estivesse considerando o amigo monge, tê-lo-ia chamado de filie (ou fili).

${ }^{46}$ Sobre Siágria, cf. Stroheker, 1948: 220; Martindale, 1980: 1041; Heinzelmann, 1982: 698-699; Pietri e Heijmans, 2013: 1843-1844.
} 
a aristocracia imperial, de modo geral, não se interessou pelo monasticismo. Por outro lado, justamente por causa desta escassez, as informações que Sidônio nos oferece sobre o patronato de grandes aristocratas e a interferência que eles podiam ter no governo e no cotidiano dos monastérios que subvencionavam são muito importantes para os estudiosos do monasticismo tardo-antigo. Informações equivalentes não podem ser encontradas em outras fontes da época.

\section{CONSIDERAÇÕES FINAIS}

Os escritos de Sidônio Apolinário suscitam questões importantes sobre a relação da aristocracia imperial galo-romana com o monasticismo. Em primeiro lugar, eles não corroboram a tese de que o monasticismo difundiu-se amplamente entre as aristocracias ocidentais até o início do século V. Pelo contrário. Eles sugerem que, até o início da década de 480, a aristocracia imperial galo-romana, de modo geral, ainda não havia se interessado pelo monasticismo. Sidônio menciona apenas seis ou sete monges provenientes desta aristocracia. Ao mesmo tempo, ele pouco fala da devoção de grandes aristocratas por monges e monastérios.

Em segundo lugar, os monges provenientes da aristocracia imperial galo-romana tendiam a converter-se após uma carreira pública. Eles continuavam a viver em suas villae e a manter suas riquezas, embora pudessem adotar determinadas restrições do luxo. Apenas Claudiano, se o considerarmos membro desta aristocracia, fugiu à regra, convertendo-se ao monasticismo ainda jovem.

Em terceiro lugar, enfim, Sidônio aproximou-se do monasticismo, muito provavelmente, por causa dos conhecimentos e da erudição de Claudiano, Fausto e Lupo. Sendo um amante das letras, Sidônio teria dificilmente admirado os monges que negavam a validade da cultura clássica ou que a consideravam incompatível com o cristianismo. Mas a aproximação de grandes aristocratas ao monasticismo podia dar-se de outras formas. $\mathrm{O}$ conde Vitório admirava Abraão, um monge de origem síria, por causa dos milagres que ele operava. A devoção de Vitório manifestava-se em doações ao próprio Abraão ou ao monastério que ele fundou em Clermont. No entanto, é possível que o maior patrono do monastério fosse Volusiano, um rico senador da Auvergne. Foi muito provavelmente por causa de seu patronato que ele pôde exercer no monastério uma autoridade maior que a do próprio abade.

\section{REFERÊNCIAS}

AGOSTINHO. Epistulae, pars I: Epistulae I-XXX. Edição de GOLDBACHER, A. Praga/ Viena/Leipzig, 1895.

ALCIATI, R. Monaci, vescovi e scuola nella Gallia tardoantica. Roma: Edizioni di Storia e Letteratura, 2009.

ANÔNIMO. Vie des Pères du Jura. Edição, tradução e comentários de MARTINE, F. Paris: Les Éditions du Cerf, 2004. 
BALMELLE, C. Les demeures aristocratiques d'Aquitaine: société et culture de l'Antiquité tardive dans le Sud-Ouest de la Gaule. Bordeaux/Paris: Ausonius/Aquitania, 2001.

BROWN, P. The Body and Society: Men, Women, and Sexual Renunciation in Early Christianity. Nova York: Columbia University Press, 1988.

BROWN, P. Through the Eye of a Needle: Wealth, the Fall of Rome, and the Making of Christianity in the West, 350-550 AD. Princeton/Oxford: Princeton University Press, 2012.

CLARK, E. A. Jerome, Chrysostom, and Friends: Essays and Translations. Nova York: Edwin Mellen Press, 1979.

CLARK, E. A. Ascetic Piety and Women's Faith: Essays on Late Ancient Christianity. Lewiston/ Queenston: Edwin Mellen Press, 1986.

CLAUDIANO. De statu animae libri tres. Edição de ENGELBRECHT, A. Viena, 1885.

DARK, K. "The Archaeological Implications of Fourth- and Fifth-Century Descriptions of Villas in the Northwest Provinces of the Roman Empire". Historia, 54 (2005), 331-342.

DE VOGÜÉ, A. Histoire littéraire du mouvement monastique dans l'antiquité: l'essor de la littérature lérinienne et les écrits contemporains (410-500). Paris: Les Éditions du Cerf, 2003, vol. 7.

DILL, S. Roman Society in the Last Century of the Western Empire. Londres: MacMillan, 1899.

ELM, S. "Virgins of God": the Making of Asceticism in Late Antiquity. Oxford: Clarendon Press, 1994.

FIGUINHA, M. C. Servos de Deus: monasticismo, poder e ortodoxia em santo Agostinho. São Paulo: Annablume, 2009.

FIGUINHA, M. C. “Questões sobre a versão feminina da Regra de santo Agostinho”. Revista Eletrônica Antiguidade Clássica, 5 (2010), 155-173.

FONTAINE, J. "L'aristocratie occidentale devant le monachisme aux IV ème et V̀̀me siècles". Rivista di storia e letteratura religiosa, 15 (1979), 28-53.

FREND, W. H. C. "Paulinus of Nola and the Last Century of the Western Empire". Journal of Roman Studies, 59 (1969), 1-11.

FREND, W. H. C. “The Two Worlds of Paulinus of Nola”. In: BINNS, J. W. (Org.). Latin Literature of the Fourth Century. Londres/Boston: Routledge/Kegan Paul, 1974, pp. 100-133.

GIARDINA, A. "Carità eversiva: le donazioni de Melania la Giovane e gli equilibri della società tardoromana”. Studi storici, 29 (1988), 127-142.

GREGÓRIO. Decem libri historiarum. Edição de KRUSCH, B.; LEVISON, W. B. Monumenta Germaniae Historica. Scriptores Rerum Merouingicarum. Hannover: Impensis Bibliopolii Hahniani, 1951, vol. 1.

GREGÓRIO. Liber uitae Patrum. Edição de KRUSCH, B. Monumenta Germaniae Historica. Scriptores Rerum Meroningicarum. Hannover, Impensis Bibliopolii Hahniani, 1969, v. 2, p. 211-294.

GRIFFE, É. La Gaule chrétienne à l'époque romaine: la cité chrétienne. Paris: Letouzey et Ané, 1965, v. 3. 
HARRIES, J. Sidonius Apollinaris and the Fall of Rome, AD 407485. Oxford: Oxford University Press, 1994.

HEINZELMANN, M. “Galliche Prosopographie, 260-527”. Francia, 10 (1982), 531-718.

HILÁRIO. Vie de saint Honorat. Edição, tradução e comentários de VALENTIN, M.-D. Paris: Les Éditions du Cerf, 1977.

JERÔNIMO. Epistulae, pars I: Epistulae I-LXX. Edição de HILBERG, I. Viena, 1910.

JONES, A. H. M.; MARTINDALE, J. R.; MORRIS, J. The Prosopography of the Later Roman Empire, AD 260-395. Cambridge: Cambridge University Press, 1971, vol. 1.

LIENHARD, J. T. Paulinus of Nola and Early Western Asceticism. Colônia/Bonn: Peter Hanstein Verlag, 1977.

MARTINDALE, J. R. The Prosopography of the Later Roman Empire, AD 395-527. Cambridge: Cambridge University Press, 1980, vol. 2.

MATHISEN, R. W. Roman Aristocrats in Barbarian Gaul: Strategies for Survival in an Age of Transition. Austin: University of Texas Press, 1993.

MATTHEWS, J. F. Western Aristocracies and Imperial Court, A.D. 364-425. Oxford: Clarendon Press, 1990.

MOMIGLIANO, A. "Introducción: el cristianismo y la decadencia del Imperio romano". In: MOMIGLIANO, A. (Org.). El conflicto entre el paganismo y el cristianismo en el siglo IV. Tradução de M. H. Iñiguez. Madri: Alianza Editorial: 1989, pp. 15-30.

NELSON, J. L. “Medieval Monasticism”. In: LINEHAN, P.; NELSON, J. L. (Orgs.). The Medieval World. Londres/NovaYork: Routledge: 2001, pp. 576-604.

PAULINO. Epistulae. Edição de HARTEL, G. Praga/Viena/Leipzig, 1894.

PERCIVAL, J. “The Fifth-Century Villa: New Life or Death Postponed?”. In: DRINKWATER, J.; ELTON, H. (Orgs.). Fifth-Century Gaul: a Crisis of Identity? Cambridge: Cambridge University Press, 1992, pp. 156-164.

PERCIVAL, J. "Desperately Seeking Sidonius: the Realities of Life in Fifth-Century Gaul". Latomus, 56 (1997), 279-292.

PIETRI, L.; HEIJMANS, M. Prosopographie chrétienne du bas-empire: la Gaule chrétienne (314-614). Paris: Association des amis du Centre d'histoire et civilisation de Byzance, 2013, 2 vols.

ROUSSEAU, P. “In Search of Sidonius the Bishop”. Historia, 25 (1976), 356-377.

RURÍCIO. Ruricii Lemonicensis epistularum libri duo. Edição de DEMEULENAERE, R. Foebadius, Victricius, Leporius, Vincentius Lerinensis, Euagrius, Ruricius. Turnhout: Brepols, 1985, pp. 312-394. 
SIDÔNIO APOLINÁRIO. Sidoine Apollinaire: Poèmes. Edição, tradução e comentários de LOYEN, A. Paris: Les Belles Lettres, 2003a, vol. 1.

SIDÔNIO APOLINÁRIO. Sidoine Apollinaire: Correspondance, livres I- $V$. Edição, tradução e comentários de LOYEN, A. Paris Les Belles Lettres, 2003b, vol. 2.

SIDÔNIO APOLINÁRIO. Sidoine Apollinaire: Correspondance, livres VI-IX. Edição, tradução e comentários de LOYEN, A. Paris Les Belles Lettres, 2003c, vol. 3.

SILVA, G. V. da. "A redefinição do papel feminino na Igreja primitiva: virgens, viúvas, diaconisas e monjas". In: SILVA, G. V. da; NADER, M. B.; FRANCO, S. P. (Orgs.). As identidades no tempo: ensaios de gênero, etnia e religião. Vitória: Edufes, 2006a, pp. 321-352.

SILVA, G. V. da. "A masculinização das devotas no século IV d.C.: Eustácio de Sebaste e as tradições heréticas do ascetismo". In: SILVA, G. V. da; NADER, M. B.; FRANCO, S. P. (Orgs.). História, mulher e poder. Vitória: Edufes, 2006b, pp. 40-59.

SILVA, G. V. da. "Ascetismo, gênero e poder no Baixo Império Romano: Paládio de Helenópolis e o status das devotas cristãs". História, 26 (2007), 63-78.

SILVA, G. V. da. "As mulheres e os perigos da cidade: casamento espiritual, virgindade e prostituição segundo João Crisóstomo”. In: SILVA, G. V. da; LEITE, L. R.; CARVALHO, R. (Orgs.). Gênero, religião e poder na Antiguidade: contribuições interdisciplinares. Vitória: GM Editora, 2012, pp. 31-49.

STROHEKER, K. F. Der senatorische Adel im spätantiken Gallien. Tübingen: Alma Mater Verlag, 1948.

SULPÍCIO SEVERO. Gallus: Dialogues sur les "vertus" de saint Martin. Edição, tradução e comentários de FONTAINE, J. com a colaboração de DUPRÉ, N. Paris: Les Éditions du Cerf, 2006.

TROUT, E. Paulinus of Nola: Life, Letters, and Poems. Berkeley/Los Angeles: University of California Press, 1999.

VISSER, J. "Sidonius Apollinaris, Ep. II.2: The Man and His Villa". Journal for Late Antique Religion and Culture, v. 8, p. 26-45, 2014.

Vita Aniani episcopi Aurelianensis. Edição de KRUSCH, B. Monumenta Germaniae Histórica. Scriptores Rerum Merouingicarum. Hannover: Impensis Bibliopolii Hahniani, 1896, pp. 104-117.

WOOD, I. N. "Continuity or Calamity? The Constraints of Literary Models". In: DRINKWATER, J.; ELTON, H. (Orgs.). Fifth-Century Gaul: a Crisis of Identity? Cambridge: Cambridge University Press, 1992, pp. 9-18.

Recebido em: 24 de fevereiro de 2015

Aprovado em: 3 de novembro de 2016 